\title{
朝 鮮人手骨の研究
}

（手根骨を除く）

岛五 郎

\section{㨋贯及び破究村料と其の方法}

手骨研究に賞り徆骨に確證のない限り指骨末節の左右を區別する事に非常なる困難 を感する。故に余は生體から撮つたレントゲン寫萁による手骨計測を試みた。

材料は 20 才上り 73 才に至る朝鮮人の手左右各男性 60 例、女性 50 例である。

レントゲン䈍㝘の撮影方法はフキルムそ掌側面を密着せしめ背側面直上(dorsovolar) 85 粯の距離上り寫したものである。

余は豫め各手骨基底面の中央と各手骨小頭媔點を骨軸の方向に貫く針金を以て組合

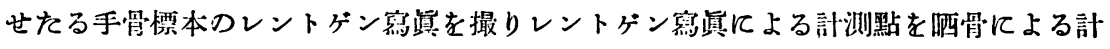
测點と一鈹せしめ様と試みたが不可能であつた。故にレントゲン寫県で例外なしに明 確に現はれる部を以て計测點とした。即ち第 I. III. IV 掌骨では其の基底掌测愁は線 状に投影されてるるが第 II. V 掌骨では此の線が明かでなく基底匡廓線が投影されて るる。指骨では全部 $(I-V)$ 基底背側棱が明かなる線狀に投影されてるる。從つて各手 骨長計测に於て第 I. III. IV 掌骨では基底掌側稜の投影線、第 II. V 掌骨では基底压

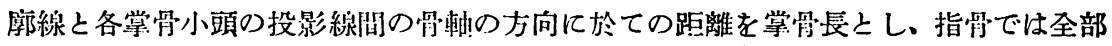
基底背側稜の投影線と各指骨小頭の投影線間の骨軸の方向に於ての距離を指骨長とし

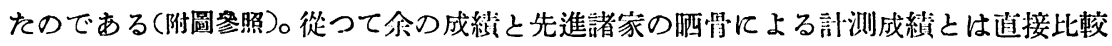
する事は州來ない。一「余の場合紹對值に於てる、本均值に於てる第II 掌骨長が最大であつ

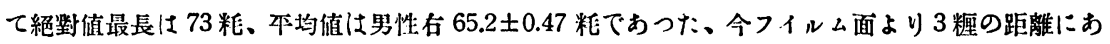

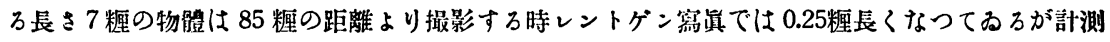
值には何れにし補正はしてない。」

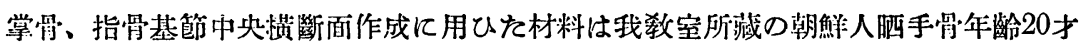
吸和 7 年 9 月 


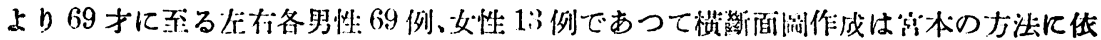
つたのである。

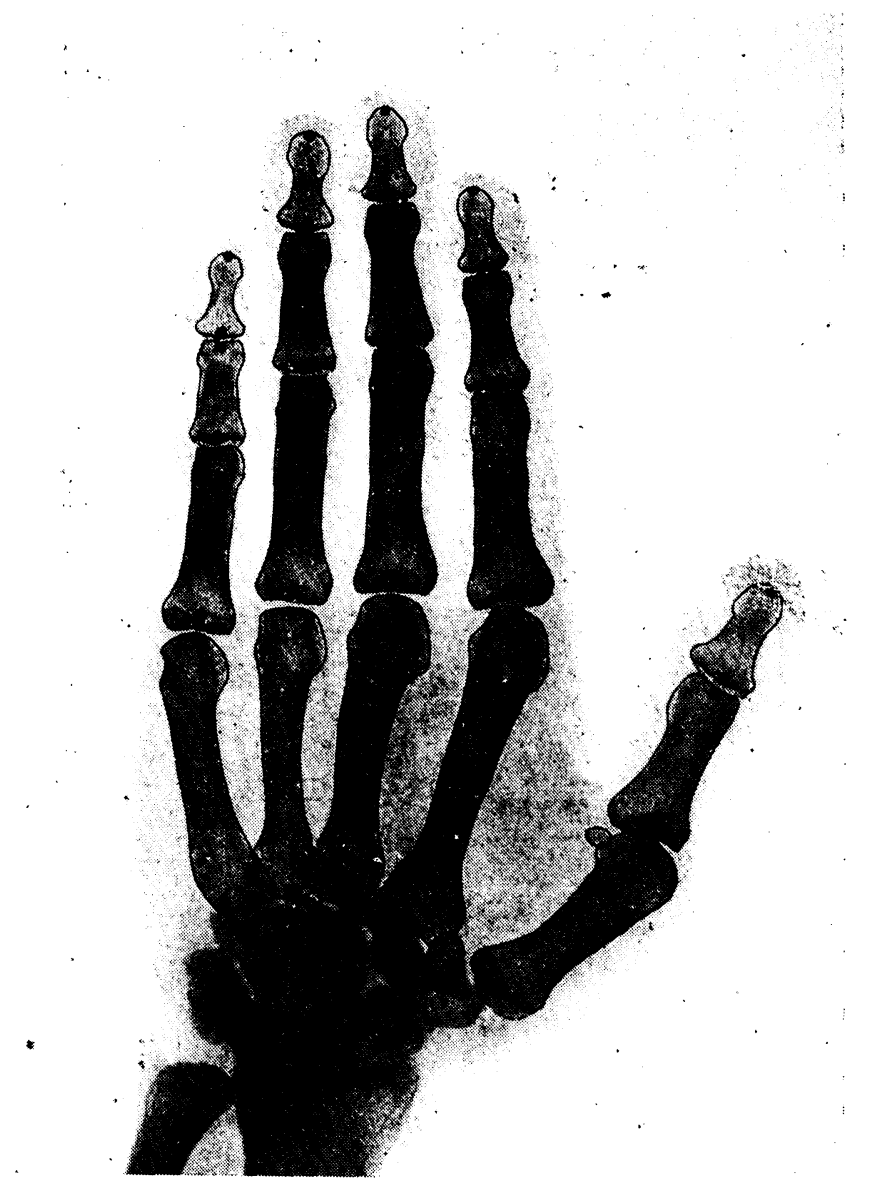

Rechte Hand, dorsovolar. Mann, 27 Jahre, Abstand $85 \mathrm{~cm}$. Messpunkten. 


\section{計 測 所 見}

Mitterwerte der Länge der Handknocher

a) Männer $(n=60)$

\begin{tabular}{|c|c|c|c|c|c|c|}
\hline & & I & II & III & IV & V \\
\hline Metacarp. & $\begin{array}{l}\text { r. } \\
\text { l. }\end{array}$ & $\begin{array}{l}44.9 \pm 0.37 \\
44.9 \pm 0.35\end{array}$ & $\begin{array}{l}65.2 \pm 0.47 \\
65.0 \pm 0.48\end{array}$ & $\begin{array}{l}62.1 \pm 0.47 \\
62.4 \pm 0.46\end{array}$ & $\begin{array}{l}56.2 \pm 0.44 \\
56.5 \pm 0.44\end{array}$ & $\begin{array}{l}52.1 \pm 0.39 \\
52.1 \pm 0.39\end{array}$ \\
\hline Grundph. & $\begin{array}{l}\text { r. } \\
\text { i. }\end{array}$ & $\begin{array}{l}28.5 \pm 0.25 \\
28.6 \pm 0.25\end{array}$ & $\begin{array}{l}38.2 \pm 0.28 \\
38.4 \pm 0.27\end{array}$ & $\begin{array}{l}43.0 \pm 0.31 \\
43.1 \pm 0.31\end{array}$ & $\begin{array}{l}40.6 \pm 0.28 \\
40.5 \pm 0.28\end{array}$ & $\begin{array}{l}31.9 \pm 0.24 \\
32.0 \pm 0.23\end{array}$ \\
\hline Mittelph. & $\begin{array}{l}\text { r. } \\
\text { l. }\end{array}$ & & $\begin{array}{l}22.3 \pm 0.22 \\
22.2 \pm 0.19\end{array}$ & $\begin{array}{l}26.8 \pm 0.23 \\
26.9 \pm 0.25\end{array}$ & $\begin{array}{l}25.6 \pm 0.23 \\
25.6 \pm 0.20\end{array}$ & $\begin{array}{l}17.8 \pm 0.22 \\
17.9 \pm 0.20\end{array}$ \\
\hline Endph. & $\begin{array}{l}\text { r. } \\
\text { l. }\end{array}$ & $\begin{array}{l}21.2 \pm 0.18 \\
21.3 \pm 0.21\end{array}$ & $\begin{array}{l}16.7 \pm 0.17 \\
16.9 \pm 0.15\end{array}$ & $\begin{array}{l}17.8 \pm 0.17 \\
17.8 \pm 0.18\end{array}$ & $\begin{array}{l}18.3 \pm 0.16 \\
18.4 \pm 0.16\end{array}$ & $\begin{array}{l}16.2 \pm 0.17 \\
16.3 \pm 0.17\end{array}$ \\
\hline Finger. & r. & $\begin{array}{l}49.7 \pm 0.39 \\
499 \pm 0.41\end{array}$ & $\begin{array}{l}77.2 \pm 0.57 \\
77.5 \pm 0.56\end{array}$ & $\begin{array}{l}87.6 \pm 0.62 \\
87.8 \pm 0.62\end{array}$ & $\begin{array}{l}84.5 \pm 0.60 \\
84.4 \pm 0.58\end{array}$ & $\begin{array}{l}65.9 \pm 0.55 \\
66.1 \pm 0.54\end{array}$ \\
\hline Strahl. & $\begin{array}{l}\text { r. } \\
\text { i. }\end{array}$ & $\begin{array}{l}94.6 \pm 0.70 \\
94.8 \pm 0.71\end{array}$ & $\begin{array}{l}142.3 \pm 0.97 \\
142.5 \pm 0.96\end{array}$ & $\begin{array}{l}149.8 \pm 1.03 \\
150.0 \pm 0.99\end{array}$ & $\begin{array}{l}140.7 \pm 0.98 \\
141.0 \pm 0.95\end{array}$ & $\begin{array}{l}118.0 \pm 0.89 \\
118.3 \pm 0.85\end{array}$ \\
\hline \multicolumn{7}{|c|}{ b) Weiber $(n=50)$} \\
\hline & & I & It & III & IV & $\mathrm{V}$ \\
\hline Metacarp. & $\begin{array}{l}\text { r. } \\
\text { i. }\end{array}$ & $\begin{array}{l}41.7 \pm 0.30 \\
41.5 \pm 0.33\end{array}$ & $\begin{array}{l}60.2 \pm 0.40 \\
60.1 \pm 0.43\end{array}$ & $\begin{array}{l}57.7 \pm 0.43 \\
57.5 \pm 0.44\end{array}$ & $\begin{array}{l}52.7 \pm 0.39 \\
52.6 \pm 0.39\end{array}$ & $\begin{array}{l}48.8 \pm 0.39 \\
48.7 \pm 0.38\end{array}$ \\
\hline Grundph. & $\begin{array}{l}\text { r. } \\
\text { i. }\end{array}$ & $\begin{array}{l}26.7 \pm 0.22 \\
26.8 \pm 0.23\end{array}$ & $\begin{array}{l}36.3 \pm 0.28 \\
36.3 \pm 0.31\end{array}$ & $\begin{array}{l}40.8 \pm 0.30 \\
40.6 \pm 0.34\end{array}$ & $\begin{array}{l}38.7 \pm 0.33 \\
38.3 \pm 0.34\end{array}$ & $\begin{array}{l}30.5 \pm 0.27 \\
30.2 \pm 0.30\end{array}$ \\
\hline Mittelph. & $\begin{array}{l}\text { r. } \\
1 .\end{array}$ & & $\begin{array}{l}21.0 \pm 0.18 \\
21.0 \pm 0.18\end{array}$ & $\begin{array}{l}25.4 \pm 0.19 \\
25.4 \pm 0.22\end{array}$ & $\begin{array}{l}24.2 \pm 0.21 \\
24.1 \pm 0.22\end{array}$ & $\begin{array}{l}16.5 \pm 0.29 \\
16.4 \pm 0.30\end{array}$ \\
\hline Endph. & $\begin{array}{l}\text { r. } \\
\text { i. }\end{array}$ & $\begin{array}{l}19.2 \pm 0.21 \\
19.2 \pm 0.21\end{array}$ & $\begin{array}{l}15.4 \pm 0.14 \\
15.4 \pm 0.15\end{array}$ & $\begin{array}{l}16.3 \pm 0.15 \\
16.5 \pm 0.14\end{array}$ & $\begin{array}{l}16.8 \pm 0.14 \\
16.8 \pm 0.13\end{array}$ & $\begin{array}{l}15.0 \pm 0.13 \\
15.0 \pm 0.15\end{array}$ \\
\hline Finger. & $\begin{array}{l}\text { r. } \\
\text { l. }\end{array}$ & $\begin{array}{l}46.0 \pm 0.34 \\
46.0 \pm 0.35\end{array}$ & $\begin{array}{l}72.7 \pm 0.50 \\
72.7 \pm 0.53\end{array}$ & $\begin{array}{l}82.4 \pm 0.55 \\
82.5 \pm 0.61\end{array}$ & $\begin{array}{l}79.6 \pm 0.60 \\
79.1 \pm 0.60\end{array}$ & $\begin{array}{l}62.0 \pm 0.56 \\
61.6 \pm 0.58\end{array}$ \\
\hline Strahl. & $\begin{array}{l}\text { r. } \\
\text { i. }\end{array}$ & $\begin{array}{l}87.7 \pm 0.57 \\
87.5 \pm 0.62\end{array}$ & $\begin{array}{l}132.9 \pm 0.86 \\
132.8 \pm 0.91\end{array}$ & $\begin{array}{l}140: 1 \pm 0.91 \\
140.0 \pm 0.99\end{array}$ & $\begin{array}{l}132.4 \pm 0.93 \\
131.6 \pm 0.93\end{array}$ & $\begin{array}{l}110.8 \pm 0.87 \\
110.3 \pm 0.88\end{array}$ \\
\hline
\end{tabular}

Differenz der Mittelwerte dèr Länge der Handknọchen der Männer und der Weiber. ( $D \pm m$. diff.)

$\begin{array}{lcccccc} & & \text { I } & \text { II } & \text { III } & \text { IV } & \text { V } \\ \text { Metacarp. } & \text { r. } & 3.2 \pm 0.47 & 5.0 \pm 0.62 & 4.4 \pm 0.64 & 3.5 \pm 0.59 & 3.3 \pm 0.55 \\ & \text { 1. } & 3.4 \pm 0.48 & 4.9 \pm 0.61 & 4.9 \pm 0.61 & 3.9 \pm 0.59 & 3.4 \pm 0.54 \\ \text { Grundph. } & \text { r. } & 1.8 \pm 0.33 & 2.1 \pm 0.41 & 2.2 \pm 0.43 & 1.9 \pm 0.43 & 1.8 \pm 0.38 \\ & \text { i. } & 1.8 \pm 0.34 & 1.9 \pm 0.40 & 2.5 \pm 0.46 & 2.3 \pm 0.44 & 1.4 \pm 0.36 \\ \text { Mittelph. } & \text { r. } & & 1.3 \pm 0.28 & 1.4 \pm 0.30 & 1.4 \pm 0.31 & 1.3 \pm 0.30 \\ & \text { i. } & & 1.2 \pm 0.26 & 2.5 \pm 0.33 & 1.5 \pm 0.30 & 1.5 \pm 0.36 \\ \text { Endph. } & \text { r. } & 2.0 \pm 0.28 & 1.3 \pm 0.22 & 1.5 \pm 0.23 & 1.5 \pm 0.21 & 1.2 \pm 0.21 \\ & \text { 1. } & 2.1 \pm 0.30 & 1.5 \pm 0.21 & 1.3 \pm 0.23 & 1.6 \pm 0.21 & 1.3 \pm 0.23 \\ \text { Finger. } & \text { r. } & 3.7 \pm 0.52 & 4.5 \pm 0.76 & 5.2 \pm 0.83 & 4.9 \pm 0.85 & 3.9 \pm 0.78 \\ & \text { 1. } & 3.9 \pm 0.54 & 4.8 \pm 0.77 & 5.3 \pm 0.87 & 5.3 \pm 0.83 & 4.5 \pm 0.79 \\ \text { Strahl. } & \text { r. } & 6.9 \pm 0.90 & 9.4 \pm 1.30 & 9.7 \pm 1.37 & 8.3 \pm 1.35 & 7.2 \pm 1.24 \\ & \text { i. } & 7.3 \pm 0.94 & 9.7 \pm 1.32 & 10.0 \pm 1.40 & 9.4 \pm 1.33 & 8.0 \pm 1.22\end{array}$


Die Reihenfolge der einzelnen Abschnitte nach ihrer absoluten Länge.

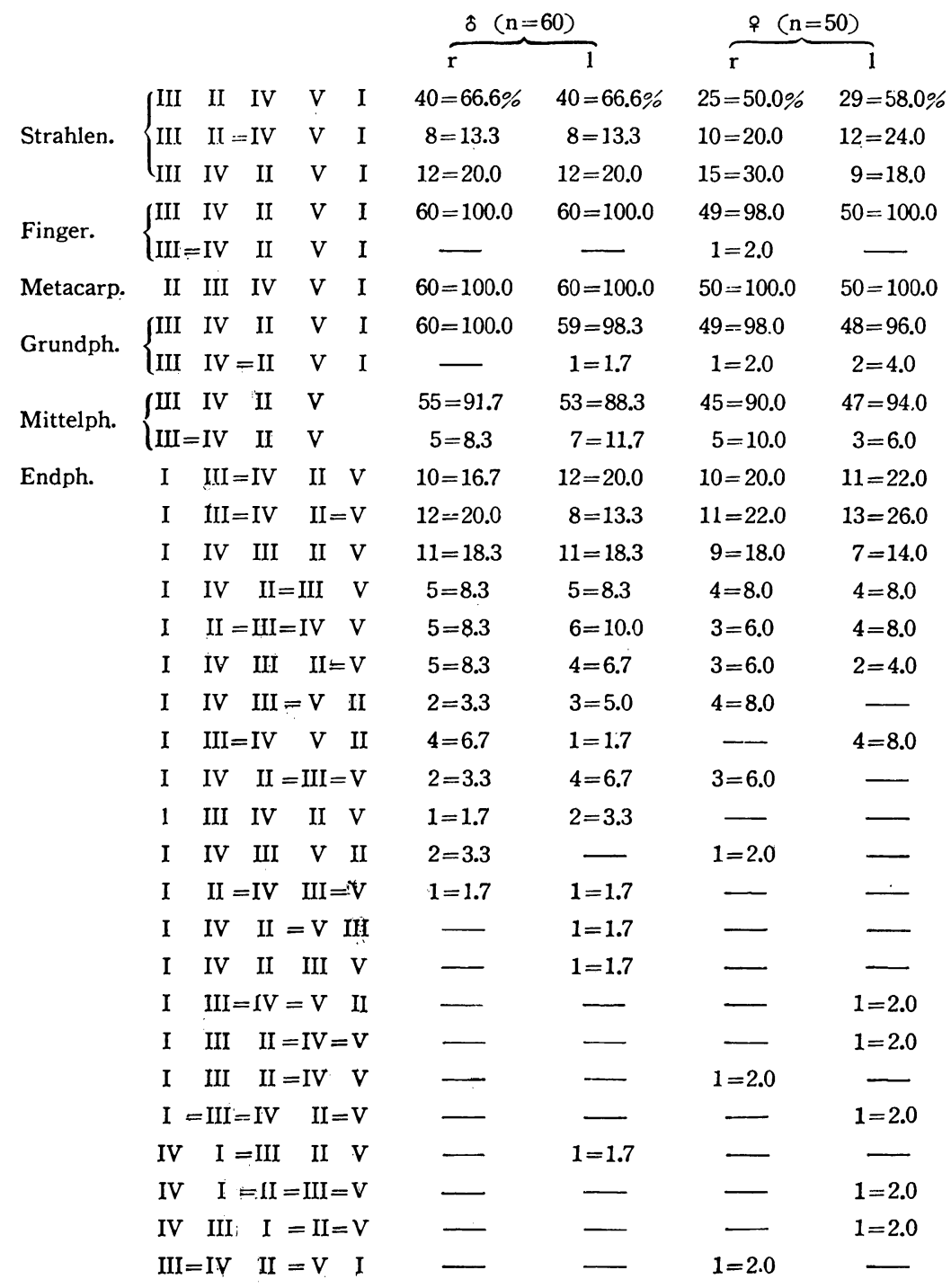


Mitterwerte der relativen Längen der Glieder der Strahlen (Stahlenlänge $=100$ )

a) Männer. $(n=60)$

\begin{tabular}{|c|c|c|c|c|c|c|}
\hline & & I & II & III & IV & $\mathrm{v}$ \\
\hline Metacarp. & $\begin{array}{l}\mathrm{r} . \\
\mathrm{i} .\end{array}$ & $\begin{array}{l}47.4 \pm 0.14 \\
47.5 \pm 0.14\end{array}$ & $\begin{array}{l}45.8 \pm 0.13 \\
45.7 \pm 0.14\end{array}$ & $\begin{array}{l}41.5 \pm 0.12 \\
41.5 \pm 0.13\end{array}$ & $\begin{array}{l}39.9 \pm 0.13 \\
40.1 \pm 0.12\end{array}$ & $\begin{array}{l}44.1 \pm 0.15 \\
44.1 \pm 0.15\end{array}$ \\
\hline Grundph. & $\begin{array}{l}\mathrm{r} . \\
\mathrm{i} .\end{array}$ & $\begin{array}{l}30.1 \pm 0.11 \\
0.2 \pm 0.12\end{array}$ & $\begin{array}{l}26.9 \pm 0.08 \\
27.0 \pm 0.08\end{array}$ & $\begin{array}{l}28.7 \pm 0.10 \\
28.7 \pm 0.10\end{array}$ & $\begin{array}{l}28.9 \pm 0.08 \\
28.8 \pm 0.08\end{array}$ & $\begin{array}{l}27.0 \pm 0.09 \\
27.0 \pm 0.09\end{array}$ \\
\hline Mittelph. & $\begin{array}{l}\text { r. } \\
\text { l. }\end{array}$ & & $\begin{array}{l}15.6 \pm 0.08 \\
15.6 \pm 0.08\end{array}$ & $\begin{array}{l}17.9 \pm 0.08 \\
17.9 \pm 0.08\end{array}$ & $\begin{array}{l}18.2 \pm 0.08 \\
18.2 \pm 0.08\end{array}$ & $\begin{array}{l}15.1 \pm 0.13 \\
15.1 \pm 0.11\end{array}$ \\
\hline Endph. & r. & $\begin{array}{l}22.5 \pm 0.12 \\
22.4 \pm 0.12\end{array}$ & $\begin{array}{l}11.8 \pm 0.09 \\
11.8 \pm 0.09\end{array}$ & $\begin{array}{l}11.9 \pm 0.08 \\
11.9 \pm 0.08\end{array}$ & $\begin{array}{l}13.0 \pm 0.08 \\
13.0 \pm 0.08\end{array}$ & $\begin{array}{l}13.7 \pm 0.10 \\
13.8 \pm 0.11\end{array}$ \\
\hline \multicolumn{7}{|c|}{ b) Weiber. $(n=50)$} \\
\hline & & I & II & III & IV & $\mathrm{V}$ \\
\hline Metacarp. & $\begin{array}{l}\text { r. } \\
\text { l. }\end{array}$ & $\begin{array}{l}47.6 \pm 0.15 \\
47.5 \pm 0.16\end{array}$ & $\begin{array}{l}45.3 \pm 0.10 \\
45.3 \pm 0.12\end{array}$ & $\begin{array}{l}41.2 \pm 0.13 \\
41.1 \pm 0.13\end{array}$ & $\begin{array}{l}39.8 \pm 0.14 \\
39.9 \pm 0.13\end{array}$ & $\begin{array}{l}44-1 \pm 0.18 \\
44.2 \pm 0.18\end{array}$ \\
\hline Grundph. & $\begin{array}{l}\text { r. } \\
\text { i. }\end{array}$ & $\begin{array}{l}30.5 \pm 0.14 \\
30.6 \pm 0.15\end{array}$ & $\begin{array}{l}27.3 \pm 0.09 \\
27.3 \pm 0.11\end{array}$ & $\begin{array}{l}29.1 \pm 0.09 \\
29.0 \pm 0.09\end{array}$ & $\begin{array}{l}29.2 \pm 0.09 \\
29.1 \pm 0.10\end{array}$ & $\begin{array}{l}27.5 \pm 0.09 \\
27.4 \pm 0.11\end{array}$ \\
\hline Mittelph. & $\begin{array}{l}\mathrm{r} . \\
\mathrm{i} .\end{array}$ & & $\begin{array}{l}15.8 \pm 0.08 \\
15.8 \pm 0.09\end{array}$ & $\begin{array}{l}18.1 \pm 0.09 \\
18.1 \pm 0.09\end{array}$ & $\begin{array}{l}18.3 \pm 0.09 \\
18.2 \pm 0.09\end{array}$ & $\begin{array}{l}14.8 \pm 0.20 \\
14.8 \pm 0.20\end{array}$ \\
\hline Endph. & r. & $\begin{array}{l}22.0 \pm 0.20 \\
22.0 \pm 0.20\end{array}$ & $\begin{array}{l}11.6 \pm 0.08 \\
11.6 \pm 0.08\end{array}$ & $\begin{array}{l}11.6 \pm 0.07 \\
11.8 \pm 0.08\end{array}$ & $\begin{array}{l}12.7 \pm 0.08 \\
12.7 \pm 0.193\end{array}$ & $\begin{array}{l}13.6 \pm 0.12 \\
13.6 \pm 0.12\end{array}$ \\
\hline
\end{tabular}

Mittelwerte der relativen Länge der Phalangen (Fingerlänge $=100$ )

a) Männer. $(n=60)$

$\begin{array}{llccccc} & & \text { I } & \text { II } & \text { III } & \text { IV } & \text { V } \\ \text { Grundph. } & \text { r. } & 57.3 \pm 0.17 & 49.5 \pm 0.16 & 49.1 \pm 0.14 & 48.1 \pm 0.12 & 48.5 \pm 0.18 \\ & \text { l. } & 57.3 \pm 0.19 & 49.6 \pm 0.14 & 49.2 \pm 0.14 & 43.0 \pm 0.12 & 48.4 \pm 0.18 \\ \text { Mittelph. } & \text { r. } & & 28.8 \pm 0.12 & 30.6 \pm 0.11 & 30.2 \pm 0.11 & 26.9 \pm 0.20 \\ & \text { l. } & & 28.7 \pm 0.11 & 30.6 \pm 0.11 & 30.3 \pm 0.11 & 27.0 \pm 0.15 \\ \text { Endph. } & \text { r. } & 42.7 \pm 0.16 & 21.7 \pm 0.14 & 20.3 \pm 0.13 & 21.6 \pm 0.12 & 24.7 \pm 0.17 \\ & \text { l. } & 42.7 \pm 0.20 & 21.8 \pm 0.13 & 20.3 \pm 0.13 & 21.7 \pm 0.11 & 24.6 \pm 0.16\end{array}$

b) Weiber. $(n=50)$

\section{I}

$\begin{array}{lll}\text { Grundph. } & \text { r. } & 58.2 \pm 0.31 \\ & \text { l. } & 58.2 \pm 0.30\end{array}$

Mittelph.

Endph.

\section{II}

$50.0 \pm 0.16$ $49.9 \pm 0.18$

$28.9 \pm 0.12$ $28.8 \pm 0.11$

$21.2 \pm 0.15$ $21.2 \pm 0.15$
III

$49.5 \pm 0 \cdot 16$ $49.2 \pm 0.16$

$30.8 \pm 0.11$ $30.8 \pm 0.12$

$19.8 \pm 0.12$ $20.0 \pm 0.13$
IV

$48.5 \pm 0.15$ $48.5 \pm 0.15$

$30.4 \pm 0.11$ $30.4 \pm 0.12$

$21.1 \pm 0.15$ $21.2 \pm 0.15$
$\mathrm{V}$

$49.2 \pm 0.23$ $49.1 \pm 0.25$

$26.5 \pm 0.31$ $26.6 \pm 0.31$

$24.3 \pm 0.21$ $24.3 \pm 0.22$

以上の諸表及び中央橫斷面(附圖)より朝鮮人手骨に就んて次の樣な事が結論される。

1. 男性手骨長は女性の夫より長い。

2. 手骨長の\%右别は兩性共に認める事が出來ない。 
3 a). 指掌骨・指骨・掌骨・基節・中節の長さは爾性其飞沃表の㥞な順序つもの が最も多ん。

$\begin{array}{llcccc}\text { Strahlen } & \text { III } & \text { II } & \text { IV } & \text { V } & \text { I } \\ \text { Finger } & \text { III } & \text { IV } & \text { II } & \text { V } & \text { I } \\ \text { Metacarpalia } & \text { II } & \text { III } & \text { IV } & \text { V } & \text { I } \\ \text { Grundphalangen } & \text { III } & \text { IV } & \text { II } & \text { V } & \text { I } \\ \text { Mittelphalangen } & \text { III } & \text { IV } & \text { II } & \text { V } & \text { I }\end{array}$

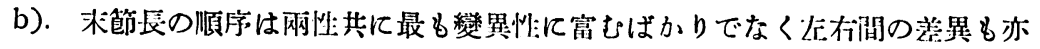
他に比して楽しんが比較的次表の樣な順序のもつが多い。

$\begin{array}{lllll}\text { I } & \text { III }= & \text { IV } & \text { II } & \text { V } \\ \text { I } & \text { III }= & \text { IV } & \text { II }= & \text { V } \\ \text { I } & \text { IV } & \text { III } & \text { II } & \text { V }\end{array}$

4. 指学骨長て對する掌骨・基節・中節・末節の唇さ・指骨表て對する基節・中節・ 米節の長さに於ては州的差異左右別を認め得ない。

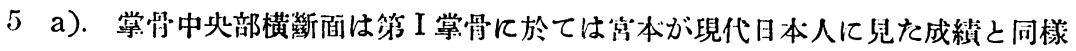
である郎その尖端を掌側方に向けた蛤形をなしてるる。第 II, III 掌骨に於ては宫本の 現代日本人に較へて第 III 掌骨より第 II 掌骨がより掌側方に向つて尖銳なるものが多 く又大さも第 III 掌骨が第 II 掌骨より大なるものが多ん事は閵の樺太アイヌに於ける 結果と一致する。第 V 掌骨䊣断面の大さは第 VI 掌骨より大なるものが多く、メそ の形の多種多栐なることは現代日本人䕁太アィヌ同梯である。

b). 手骨基節 (II-V) 橫斷面は掌側面を直徑とする牛圆形をなし、その兩縁に 小突出(Leiste の切口)が見られるのが多く此の小突怙が明かでその內側に溝を認める梯 なものでも足立の歐洲人に於ける样な弧㹜の高まりを見るてとは少なく䦽線狀をなし てるるものが多ん即ち日本人と同㥞な結果を示して居る。

大さは第 III 最大・第 V 最小・第II, IV は中間に位し殆んど同大である。

c). 掌骨、指骨基節中央横斷面共に男性は一般に女性より大きん。 （京城帝國大學醫學部解剖學教室） 


\section{主要 女 触}

(1) ADACHI, B. u. ADACHI, Y., 1905, Die Handknochen der Japaner. (Anatomischen Untersuchungen an Japanern, VIII.) Mitt. med. Fak. Univ. Tokyo, Bd. 6, S. 349-375.

(2) Bonin, G. von., 1931, Preliminary Study of the Northern Chinese Hand. Anthrop. Anz. Vol. VII. S. 241-256.

(3) Braune u. Fischer, O., 1887, Die Länge der Finger und Metacarpalknochen der menschlichen Hand. Arch. Anat. Physiol. Anat. Abt. S. 107.

（4）宮本博人. 大正 14 年現代日本人人肖の人類學的研究第二部 上肢尚の研究 人類學雜誌第 40 卷 6.7 .8 号虎拔刷。

(5) Miyaminto, H., 1926, Morphologische Untersuchung über die Querschnitte der Röhrenknochen der rezenten Japaner. I. Morphologische Untersuchung über die Querschnitte der Knochen der oberen Extremität. Act. Schol. med. Univ. Imper. in Kioto. Vol. VII. S. 553-567.

(6) Martin, R., 1928, Lehrbuch der Anthropologie.

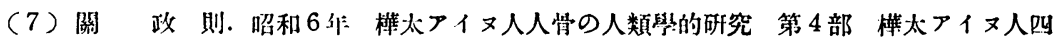
肢管狀骨横到面の人類學的研究人類學雜誌 第 46 卷 5.6.7 號附錄

( 8 ) Uhlipach, R., 1914, Messungen an Hand und Fussskeletten von Hottentotten. Zschr. Morphol. Anthrop. Bd. 16, S. 449. 


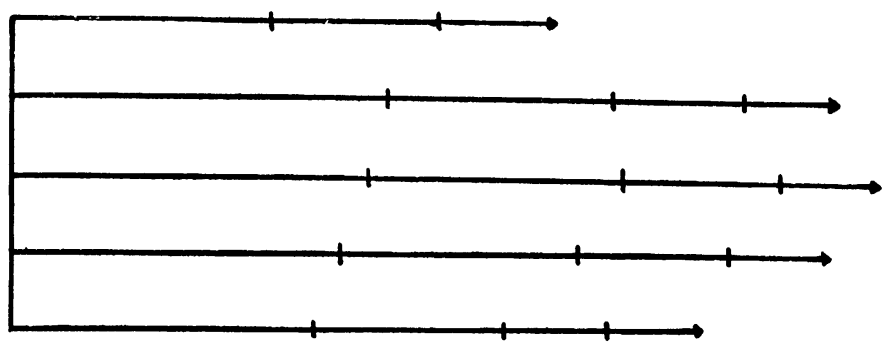

of

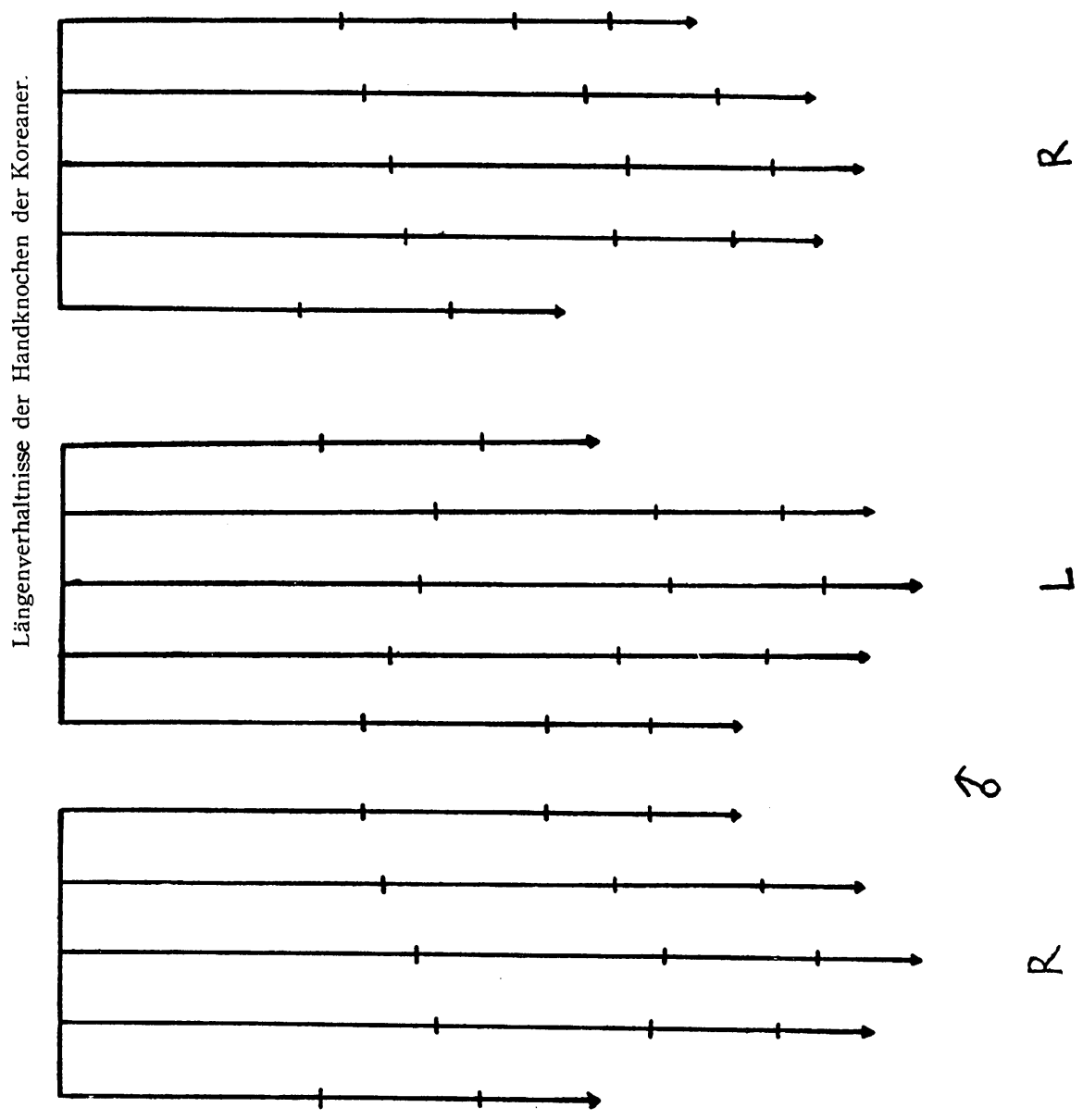


Guerschnitte durch die Mitte der Ossa metacarpalia ( $\frac{1}{1.00}$ Grässe.)

\section{占}

(1) $0000^{\text {no. }} 0000$ (8)

00000 n.2 00000

$00000^{n .3} 00000$

00000 n.t 00000

$00000^{10.5} 00000$

$00000^{n .6} 00000$

$00000^{\text {nat }} 00000$

00000 k.s 00000

00000 n.9. 00000

$00000^{\text {k.10 }} 00000$

吗和 7 电 9 月 
00000 r.ll 00000

$00000_{\text {un12 }} 00000$

00000 n 00000

$00000_{\text {nut }} 00000$

00000 w.s 00000

00000 w 00000

00000 min 00000

00000 w.s 00000

00000 w 00000

$00000_{\text {wat }} 00000$ 
$00000_{1.21}^{0} 000$ (1)

00000 ress 00000

00000 ness 00000

0000 nst $_{\text {ns }} 00000$

00000 wes 00000

00000 was 00000

$00000_{\text {men }} 00000$

00000 wer 00000

00000 wes 00000

$00000_{k, 30} 00000$ 
$00000^{k 31} 00000$

$00000_{\text {nas }} 00000$

$00000_{\text {n.33 }} 00000$

$00000_{\text {n.34 }} 00000$

$00000_{\text {nas }} 00000$

$00000_{\text {nas6 }} 00000$

00000 wat 00000

$00000_{\text {n.ss }} 00000$

$00000_{\text {mis }} 00000$

$00000_{n+40} 00000$ 
00000 unt 0000 (1)

$00000_{\text {notz }} 00000$

00000 nis 00000

00000 w.4. 00000

$00000^{n+5} 00000$

00000 wat 00000

00000 nat 00000

$00000 \mathrm{x}+\mathrm{s} 00000$

00000 w w 00000

$00000_{1.50} 00000$ 
00000 n:si 00000

00000 nosz 00000

00000 was3 00000

00000 nst 00000

$00000_{\text {n.s5 }} 00000$

00000 n.s: 00000

00000 x:51 00000

00000 n:s 00000

00000 usi 00000

00000 n.0 00000 
島一朝鮮人手骨の政究

351

(1) $000 \bigcirc$ n.61 $^{\circ} \bigcirc 000$ (1)

00000 r.62 00000

우

$00000^{r .1} 00000$

00000 nar 00000

$00000^{m .3} 00000$

$00000 n_{4+4} \circ 000$

00000 n.5 00000

00000 u. 00000

$0 \triangle 000$ k 00000

00000 m o 0000

00000 n. 00000 
00000 w 00000 00000 m 00000

00000 rar 00000

00000 ke1s 00000 
鳥一朝鮮人手省の砸究

353

Querschnitte in der Mitte der Grundphalangen ( $\frac{1}{1.04}$ Grösse) $\uparrow$

( $0000 n_{0.1} 00000$

$\bigcirc 0$

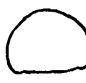

$\bigcirc n_{02}$
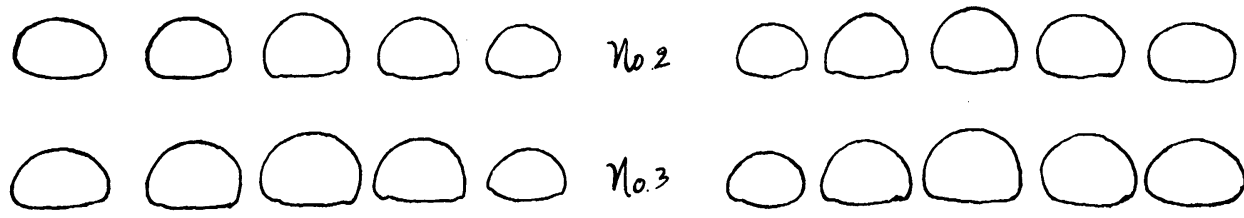

$n 0.3$
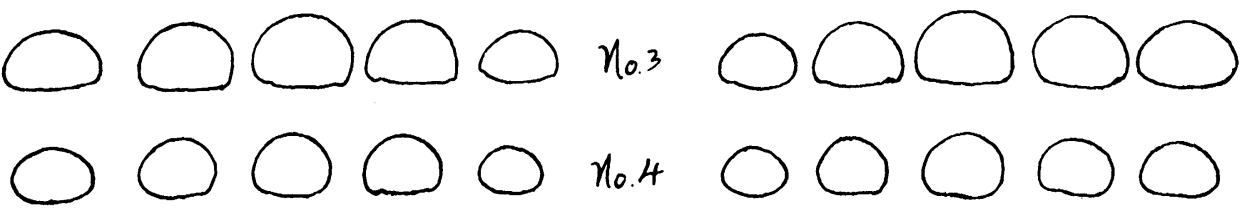

no.4 $\bigcirc$
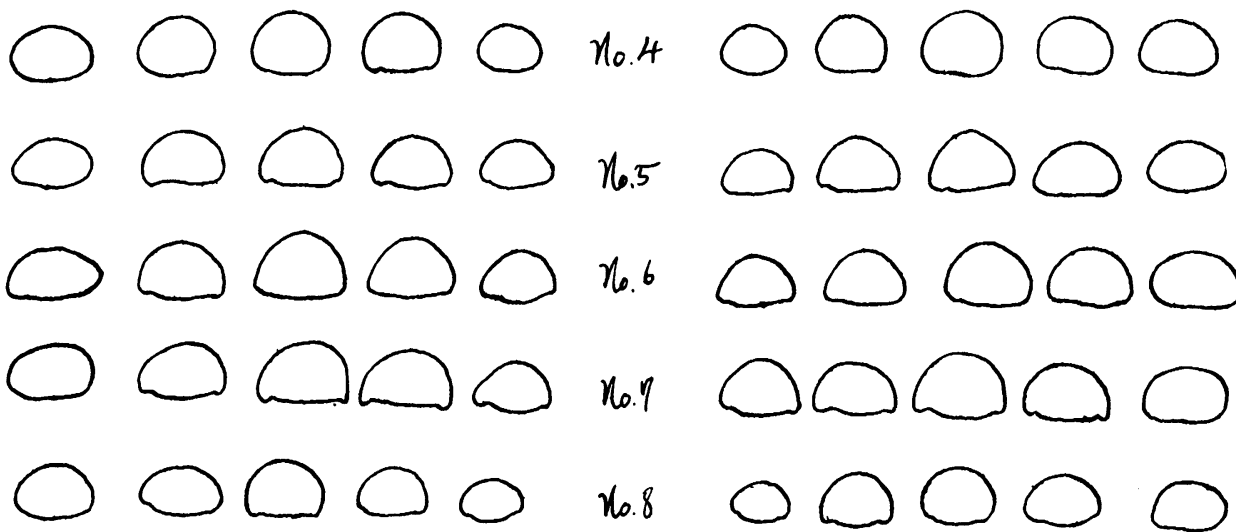

$\bigcirc \quad x_{0.8}$

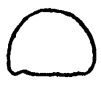

$\bigcirc x_{0.9}$
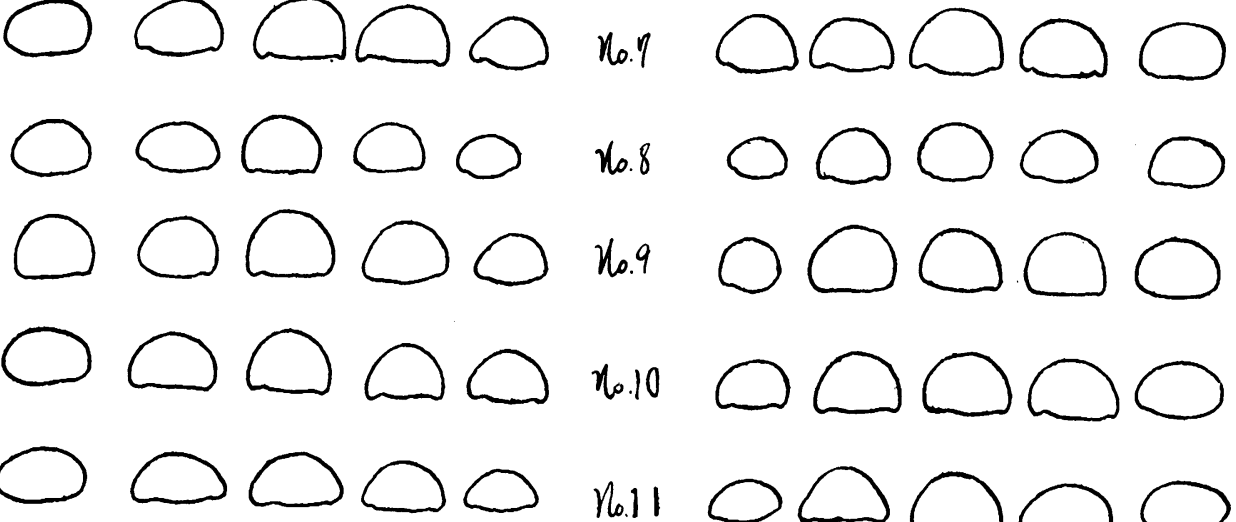

$x_{0.10}$ 0
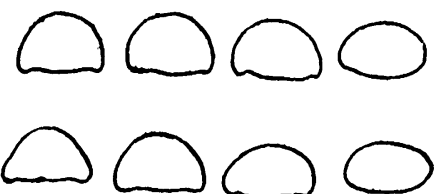

$\bigcirc$<smiles>[CH]</smiles><smiles></smiles>

$n .11$
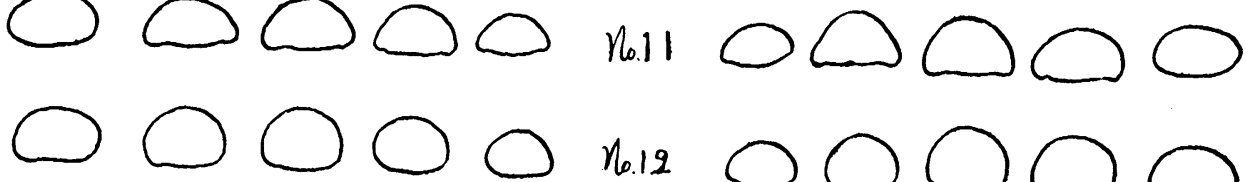

○. $n_{0.12}$ $\bigcirc$ 0 $\bigcirc$ 0

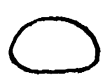

昭和 7 年 9 月 


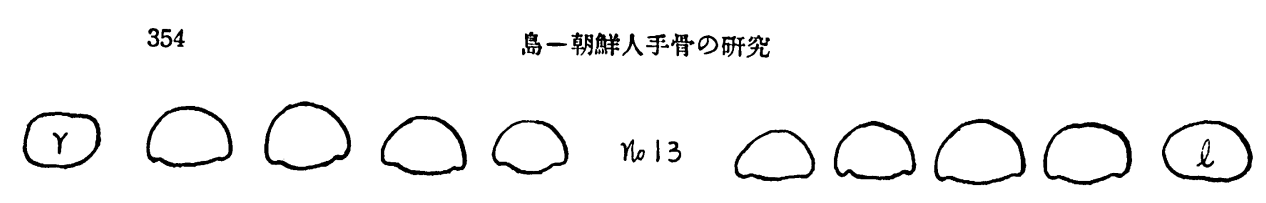

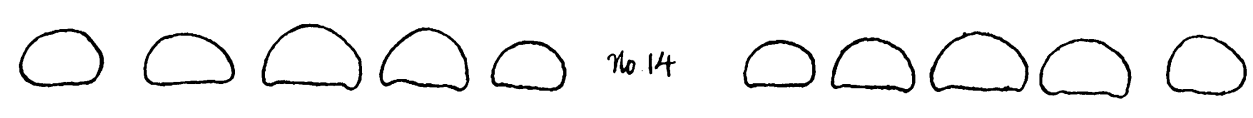

00000 w 00000

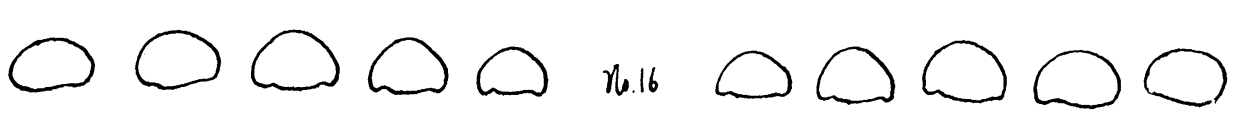

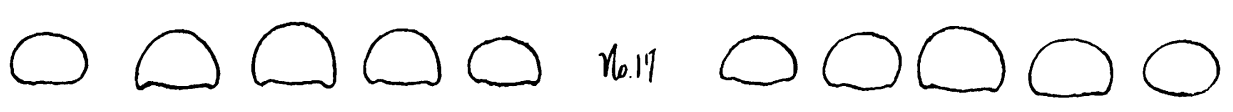

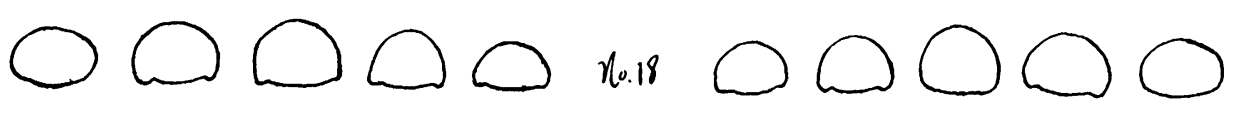

00000 m 00000

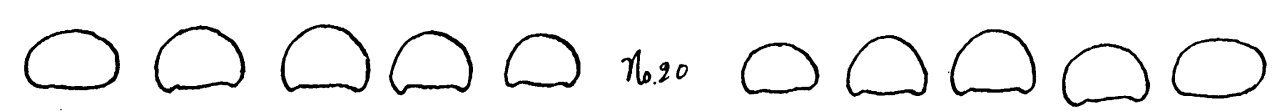

$00000 x+10000$

ODDDO man ODDO

○ 0000 res o 0000

00000 w 00000 


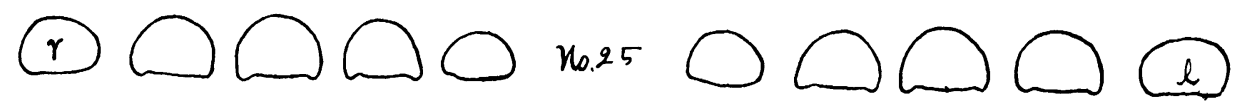

$00000 k_{2 r} 00000$

00000 nar 00000

00000 mas 00000

00000 w 00000

00000 nim o 0000

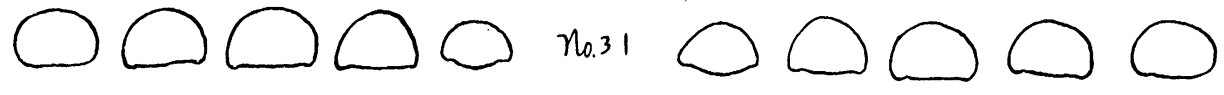

00000 mis 00000

00000 mas 00000

00000 ress 00000

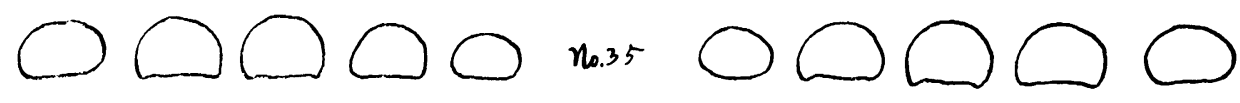

$00000 x_{3.36} 00000$ 


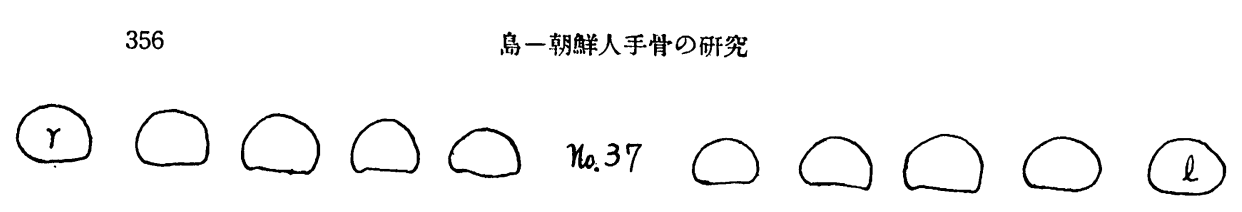

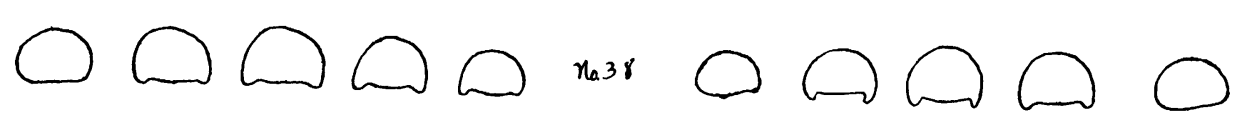

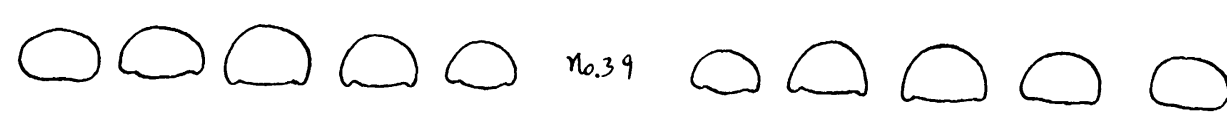
00000 nu 00000 00000 nil 00000 00000 nis 00000

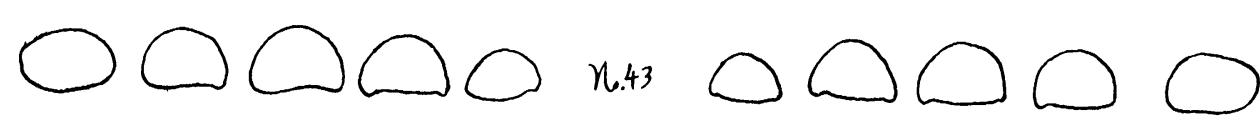
00000 w 00000 00000 w 00000 00000 nu 00000 $00000 \mathrm{~m}$ o 0000 00000 nats 00000 


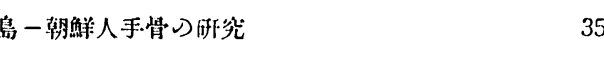

$00000 \times 400000$

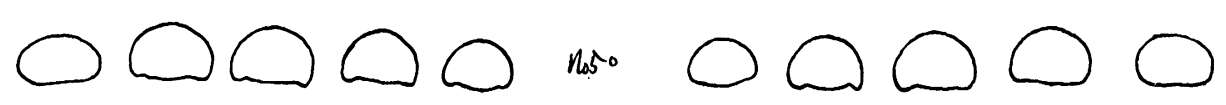

00000 w 00000

00000 nis 00000

00000 m 00000

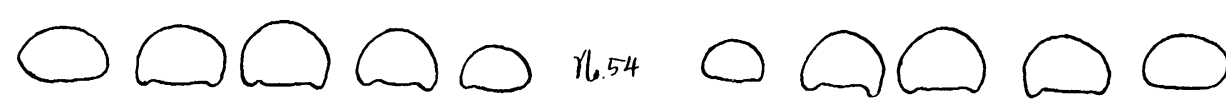

$00000 n^{45} 00000$

00000 n.6 00000

00000 m.51 00000

ODڤDOn: DQDDO

- DDDO nsi DODDO

00000 m 00000 


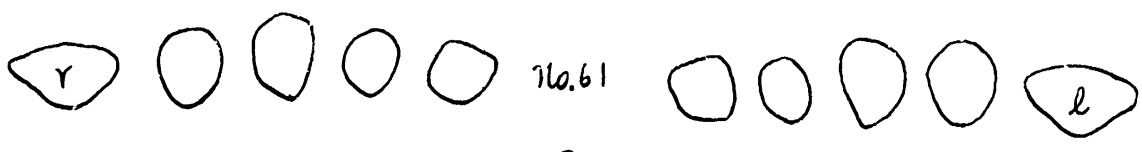
우

00000 n.1 0000 (d)

00000 n.2 00000

$00000^{n .3} 00000$

$0000 n_{n .4} 00000$

$00000^{n .5} 00000$

00000 r.6 00000

00000 nat 00000

00000 m.s 00000

$00000 \mathrm{~m} \cdot 00000$ 